\title{
تفعيل دور التقنيات التربوية في تعليم ذوي صعوبات التعلم النمائية
}

\section{أ. ربيعة أحمد الصديق كريم}

\section{كلية الآداب - جامعة مصراتة}

\section{مستخلص البحث:}

يعد مجال صعوبات التعلم من المجالات التي شغلت ومازالت تشغل اهتمام الكثيرين من التربويين لما لها من ثأثير في قدرات الطالب على التعليم والتعلم، وقد بُنلت العديد من الجهود في سبيل تحديد خصائص ذوي صعوبات التعلم، والتعرف على تلك الصعوبات وتصنيفاتما المختلفة، كما أن التقدم الحالي في مجال تكنولوجيا التعلم قد أسفر عن امكانية تسهيل عمليتى التعليم والتعلم باستخدام الوسائل، والتقنيات مما حوّل دور المتعلم من شارح للمعلومات إلى لئل مُيسر لعمليتي التعليم والتعلم، ومن تم قدمت الورقه البحثية الحالية رؤية نظرية لآليات تفعيل التقنيات التربوية في تعلم ذوي صعوبات التعلم النمائية، حيث قدمت إطاراً نظرياً عن صعوبات التعلم النمائية موضحة العوامل والتصنيفات مع تناول بعض التقنيات التربوية، وتوضيح آليات استخدامها في التغلب على تلك الصعوبات.

\section{مقدمة البحث:}

تعد العملية التربوية من العمليات التي تمر بمراحل عديدة من التطور والنمو المستمر، لما يطرأ عليها من تغيرات في نواح عديدة ومتنوعة، فلم تعد العملية التعليمية قائمة فقط على المعلم

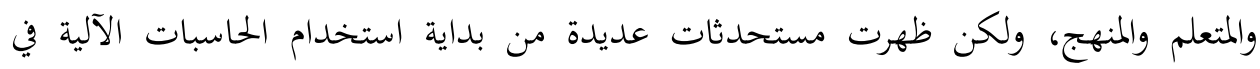
التعليم ونهايةً بالتعليم المفتوح والتعليم الإلكتروني.

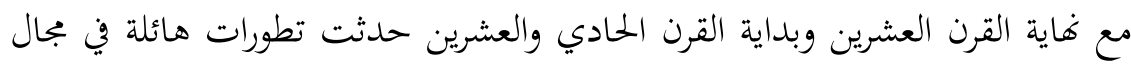

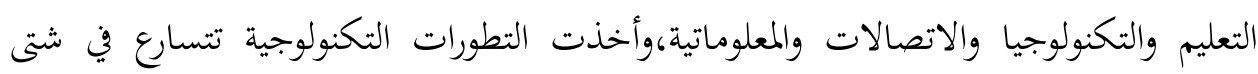
مجالات الحياة، ومن أبرز تلك المجالات استخدام التقنيات الحديثة في مجال التنمية الاقتصادية والاجتماعية، وانعكس ذلك على مجال التعليم وأصبح لزامًا على المعلم أن يستفيد من التقنيات الحديثة من أجل تحقيق التنمية، وإعداد القوى البشرية اللازمة للتنمية الاقتصادية والاجتماعية 
خاصة التقنية، حيث تعد من عوامل تقدم كل المجتمعات، وذلك لمزيد من الاستفادة من التقدم العلمي.

الجدير بالذكر أن استخدام التكنولوجيا في التعليم أصبح من ضروريات تطوير المناهج؛ لما يتميز

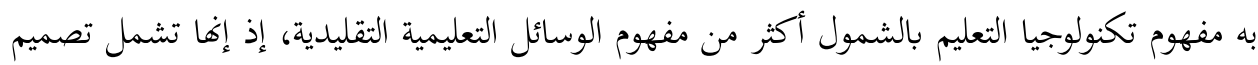
التعليم بداية من تحديد مستوى الدارسين، وتحديد الاهداف التعليمية، وتحليل المستوى، وتحديد طرق العرض، ومكونات أخرى مرتبطة بتطوير التصميم. ( حممود، 2008، 5-6). وأشارت دراسة عبد العزيز العصيمي (2005) إن استخدام التقنيات الحديثة في التعليم وتوظيفها بشكل فعال، يجعلها جزء مهم من هذه المنظومة المستهدفة بتسخير التقنيات التعليمية في تعليمهم على ضرورة تطويع التقنية الحديثة في خدمة وتعليم ذوى الاحتياجات الخاصة، واستخدام التقنيات التعليمية في تحقيق كثير من أهداف التربية الخاصة مثل: تطبيق الخطة التربوية الفردية التي تتعامل مع التلميذ بشكل فردي بناءً على قدراته وإمكاناته، ولن يتم تحقق هذه الاهداف إلا بتوفر عدد من العناصر المهمة كالمعلم المؤهل، بالاضافة إلى توفير وسائل التقنية

الهادفة والدعم المادي والفني. ( العصيمي، 2015، 2. 2. فهناك تقديرات أشارت أن ما يقرب من 5\% من من طلبة المدارس لديهم صعوبات تعلمية، وبذلك فإن هذه الفئة تمثل واحدة من أكثر فئات ذوي الاحتياجات الخاصة انتشاراً، إن لم تكن الأكثر على الإطلاق. (Lewis \& Darlag,1987). وهذه الفئة محيرة وغامضة، فمع أن ذكاء الطالب ذي صعوبات التعلم طبيعي إلا أنه يعاني من ضعف الانتباه أو الادراك أو الذاكرة، ويتعلم بعض المهارات والمفاهيم بسرعة وبيسر ولكنه يواجه

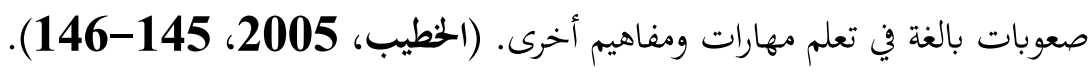

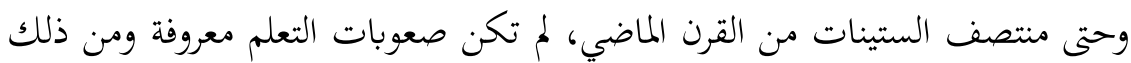

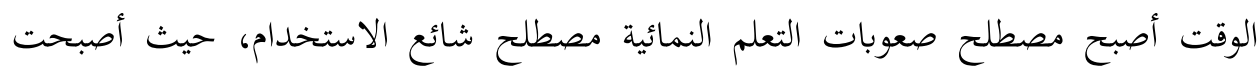
الحاجات التربوية الخاصة بهذه الفئة محددة الخصائص وأمكن التعرف على الأسباب المؤدية لها. 
وكذلك تمكن العاملين في ميدان صعوبات التعلم من تطوير وسائل وأساليب تعليمية

مكيفة لمؤلاء الاطفال الذين لديهم صعوبات تعلم. ( جذوع، 2007، 11). وهذه الفئة تختلف عن الطبيعيين في سرعة التعلم نظراً لقصور في العمليات العقلية الأساسية المهددة للتعلم الجيد. وستعتمد الباحثة على جمع وتحليل البيانات من الادبيات وبعض الدراسات السابقة التي سيتم مناقشتها لاحقاً علماً بأن البحث الحالي يقدم وكليل البيات رؤية نظرية فقط؛ لتوضيح آلية

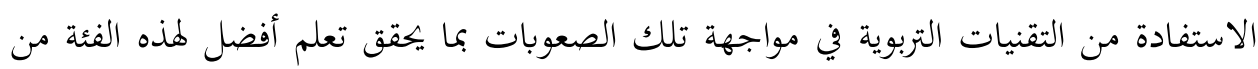
الأفراد.

\section{مشكلة البحث:}

يعد تصنيف الظواهر التعليمية على نحو خاطئ من الأسباب الرئيسة لتوجيه البرامج التعليمية إلى مسارات أخرى غير المسار الذي يجب أن توجه إليه، فانخفاض تحصيل فئة معينة من المتعلمين قد يفسره المعلم على أنه انخفاض في التحصيل يرجع إلى أن المتعلم بطئ في قدرته

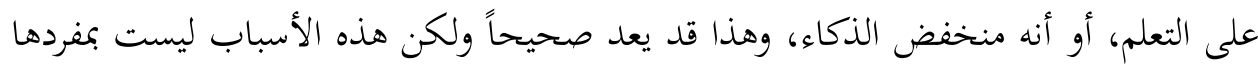
المفسرة لانخفاض التحصيل، فهناك فئة من الطلاب ذكائهم في المتوسط العام وقدراهم العقلية ملاءمة، ولكن لديهم من الصعوبات ما يحول دون تحقيق مستوى ملائم من التحصيل الأكاديمي، وهذه الفئة يطلق عليهم ذوي صعوبات التعلم.

ومن خلال عمل الباحثة كعضو تدريس وقيامها بتدريس مادة صعوبات التعلم، فقد لاحظت أن هناك قصور في توظيف التقنيات التعليمية من قبلنا داخل القاعة الدراسية، مما يشير إلى غياب دور التقنيات التربوية في التعليم والاستفادة منها. و يأتي شعور الباحثة بمشكلة البحث أيضاً أثناء دراستها - في أغلب المراحل الدراسيةوتدريسها في مدرسة خاصة اتضح لما بأن إجراءات التدريس المتبعة في المدارس، يفتقر المعلمون

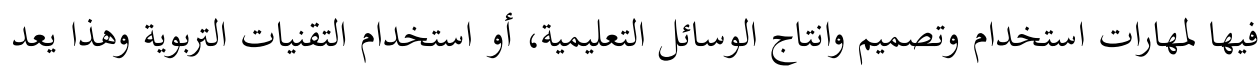
قصوراً في تحقيق أهداف المنهج في حين أن التقنيات التربوية بأنواعها المختلفة السمعية أو 
البصرية أو السمعية البصرية بما تتسم به من عناصر التشويق والاثارة تخاطب حواس المتعلم وتحافظ على انتباهه وهذا غير متوفر في بيئتا التعليمية. ويذكر الزيات أن العديد من الدراسات تشير إلى أن صعوبات التعلم النمائية في تزايد

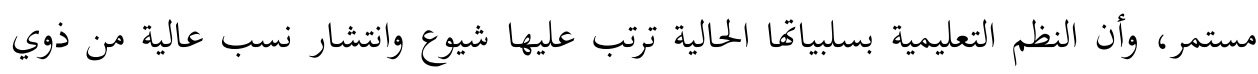
صعوبات التعلم النمائية داخل الفصول الدراسية. ( الزيات، 2000، 24 24).

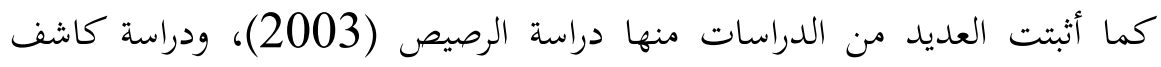

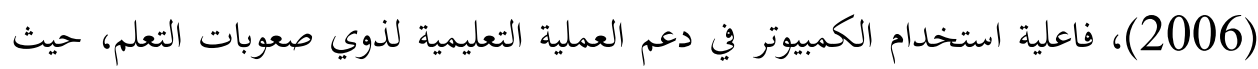
وجد أن الطلبة الذين تم اخضاعهم لبرنامج التدريب والتعلم باستخدام الكمبيوتر أظهرت تحسن واضح في معالجة مشكلات القراءة والإملاء والمهارات الحسابية كصعوبات أكاديمية، وفاعلية برنامج الحاسوب في خفض التوتر، والنشاط الزائد مقارنة بالطلبة الذين لم يخضعوا لهذا التدريب. ومن ثم فلمتوقع عند استخدام التقنيات التربوية نتغلب على معظم هذه الصعوبات النمائية، وهذا ما تحاول الباحثة توضيحه وكيفية تفعيله في هذا البحث. ومن هنا تحددت مشكلة البحث الحالي في السؤال الآتي: كيف يمكن تفعيل التقنيات التربوية في تعليم ذوي صعوبات التعلم النمائية؟ أهداف البحث: يهدف البحث الحالي إلى: تحديد آليات تفعيل التقنيات التربوية في تعليم ذوي صعوبات التعلم النمائية. أهمية البحث: تكمن أهمية البحث الحالي في الآتي: 1. كونه أول بحث يتناول التقنيات التربوية ودورها في تعليم ذوي صعوبات التعلم النمائية بليبيا على حد علم الباحثة. 2. يمكن أن يفيد المعلمين بالمدارس بكيفية التعامل مع صعوبات التعلم النمائية التي يعاني منها بعض التلاميذ. 
3. إعطاء رؤية نظرية عن كيفية تفعيل التقنيات التربوية بما يساعد المعلم في التغلب على

$$
\text { صعوبات التعلم النمائية كلٍ على حده. }
$$

4. الاسهام في الوقوف على أهم المعوقات التي تحول دون استخدام معلمي ذوي

$$
\text { صعوبات التعلم للتقنيات التعليمية في التدريس. }
$$

5. تحقيق إضافة علمية وتربوية للبحث التربوي لقلة الدراسات السابقة في مجال

استخدام معلمي ومعلمات ذوي صعوبات التعلم للتقنيات التعليمية في ليبيا على حد علم الباحثة.

$$
\text { حدود البحث: اقتصرت حدود هذا البحث على ما يلي: }
$$

الحدود الموضوعية: التعرف على دور التقنيات التربوية في تعليم ذوي صعوبات التعلم

النمائية.

الحدود الزمنية: تم إجراء البحث الحالي الفصل الدراسي ربيع 2014-2015م.

الحدود البشرية: الفئة العمرية التي تقصدها الباحثة هي تلاميذ المرحلة الابتدائية.

$$
\text { مصطلحات البحث: الحدود المكانية: تم إجراء البحث الحالي في مدينة مصراتة. }
$$

1. التقنيات التربوية Educational Techniques: هي مجموعة الأدوات والأجهزة المستخدمة في التربية والتعليم، حيث شاع في الآونة الأخيرة استخدام هذا المصطلح ليشمل الوسائل التعليمية الحديثة كالأنترنت والآلات الرقمية وغيرها من وسائل الاتصال.

\section{(السعود، 2008، 23).}

وتعرف أيضاً أفها: عملية متكاملة تعتمد على المزج بين العنصر البشرى والاجهزة وفق خطوات وإجراءات علمية تستهدف توظيف المستحدثات التكنولوجية في العملية التعليمية من أجل زيادة فاعليه وكفاءة التعليم. (عحمود، 2008، 20). 2. صعوبات النعلم النمائية developmental learning disabilities: هي قصور في الوظائف الدماغية والعمليات العقلية والمعرفية التي يحتاجها الطفل في تحصيله 
الأكاديمي، ويمكن تقسيمها إلى نوعين صعوبات أولية مثل: الانتباه، والادراك، والذاكرة،

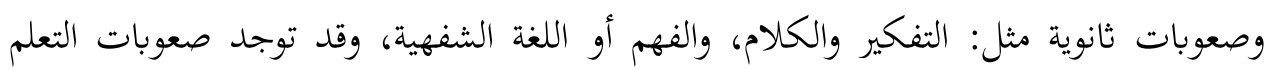
النمائية لدى الطفل في مجالات أساسية ثلاث هي: النمو اللغوي، والنمو المعرفي، ونمو المهارات

البصرية الحركية (كريم، 2009، 77). وتعرفها الباحثة إجرائيّا أفها: خلل في بعض الوظائف الدماغية، ينتج عنها قصور في العمليات العقلية الأساسية كالانتباه والادراك والذاكرة، مما يؤثر على قدرة الطالب على التعلم بشكل طبيعي مقارنة بزملائه من هم في سنه وصفه الدراسي. 3. أما التلاميذ ذوو صعوبات التعلم النمائية disabled

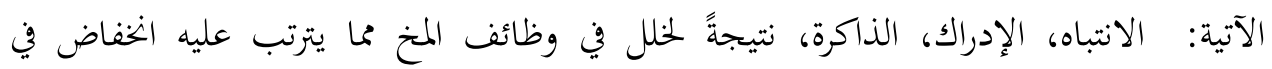
التحصيل والقدرة على التعلم بشكل عام.

منهج البحث: استخدمت الباحثة المنهج الوصفي التحليلي، وهو المنهج الذي يهتم بوصف الظاهرة موضوع الدراسة وجمع بيانات دقيقة خاصة بها مع تصنيفها وتنظيمها، والتعبير عنها بطرق كيفية وكمية، بحيث يؤدي ذلك إلى الوصول لاستنتاجات وتعميمات تساعد في تطوير الواقع.

\section{خطوات البحث:}

1. قامت الباحثة بالاطلاع على مجموعة من الكتب والدراسات السابقة لإرساء الإطار النظري للبحث الحالي والاستفادة منه في كيفية تفعيل التقنيات التربوية في تعليم ذوي صعوبات التعلم النمائية. 2. تحديد المرحلة الابتدائية موضوعاً للبحث الحالي. 3. عرض مجموعة من الدراسات السابقة التي لها علاقة بموضوع البحث الحمالي ومناقشتها.

4. اقتراح بعض الاليات لتفعيل التقنيات التربوية في علاج صعوبات التعلم النمائية. 
5. بناءً على اطلاع الباحثة على الأدبيات والدراسات السابقة أوصت بعض

التوصيات والمقترحات التي تعد منطلقاً لمشروع بحوث أخرى يمكن دراستها في المستقبل. 6. كتابة خلاصة وخاتمة للبحث الحالي.

الإطار النظري

- الخور الأول: صعوبات التعلم

مفهوم ذوي صعوبات التعلم: هم من لديهم قدرة ذكائية عقلية متوسطة، ويعانون

من صعوبة في التعلم ناتحة عن خلل دماغي في الجهاز العصبي المركزي مما يؤثر على المهارات

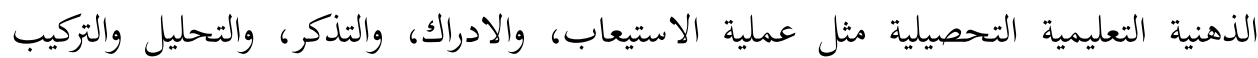
والتميز في المجالات العلمية مثل القراءة والكتابة، والحساب، والتي تؤثر على تصرفاته، وقدرته

على التأقلم، والتكيف مع البيئة. (نبيل، وآخرون، 2000، 149). خصائص التعلم لذوي صعوبات التعلم: 1. الحركة الزائدة بسبب قصور الانتباه في مداه وسعته.

$$
\begin{aligned}
& \text { 2. قصور في الإدراك الحركي. } \\
& \text { 3. القهرية (لديه سلوك قصري لا إرادي). } \\
& \text { 4. اضطرابات في الانتباه. } \\
& \text { 5. اضطرابات في الذاكرة والتفكير. }
\end{aligned}
$$

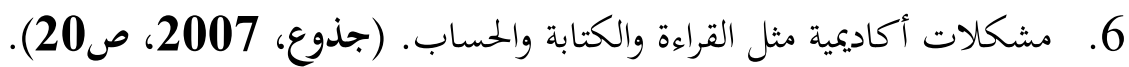
الحُصائص التي يمكن للمعلم من خلالما التعرف على هذه الفئة:

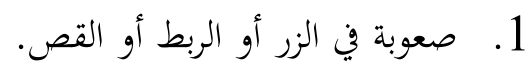
2. صعوبة في فهم الكلمات الدالة على التوجه المكاني. 3. ـ صعوبة في تنفيذ أكثر من طلب. 4. تطور بطىء في الكلام مع تقديم أو تأخير حروف الكلمة الواحدة. 5. 5 معاناة في تذكر الأشياء المرتبة. 


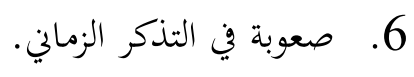

7. الشعور بالتعب نتيجة التركيز الكبير، والجهد المبذول في التعلم، وتستمر هذه التها.

الأعراض في المدرسة الابتدائية بالاضافة إلى:

أ. صعوبة في التمييز بين الكلمات والحروف المتقاربة في الشكل وتقسيم الكلمات

$$
\text { الطويلة إلى مقاطع أو وضعها في التريب الصحيح لتكون كلمة. }
$$

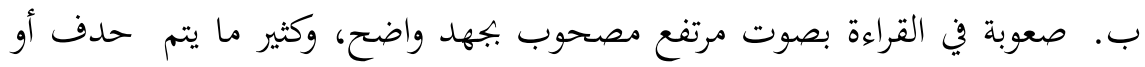

$$
\text { زيادة بعض الكلمات أو حذف سطر أو قراءة سطر مرتين. }
$$

$$
\text { ج. عدم الانتباه إلى علامات الترقيم. }
$$

د. صعوبة في حفظ جدول الضرب واكتساب المفاهيم الرياضية.

هـ. صعوبة في الربط بين صوت الحرف وشكله كتابة الكلمة بتهجئة مختلفة في الفقرة

$$
\text { نفسها. (الزبيدي، 2007، } 179 \text { 180 180). }
$$

تصنف صعوبات التعلم إلى صعوبات تعلم نمائية وتشمل صعوبات الانتباه، والادراك، والذاكرة، أما صعوبات التعلم الأكاديمية فتشمل صعوبات القراءة والكتابة، والحساب.

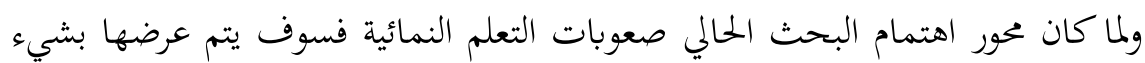
من التفصيل.

$$
\text { أولا: صعوبات الانتباه: }
$$

تعريف الانتباه: يمكن تعريفه بأنه عملية يقوم بها الفرد باختيار مثيرات محددة وتركيزه

على هذه المنبهات التي يواجهها في حياته. (كوافحه، 2004، 80). أهمية الانتباه في عمليتي التعليم والتعلم:

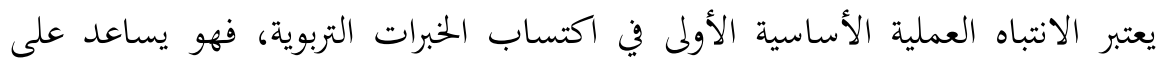
تركيز حواس الطفل فيما يقدم له من معلومات، ويجعله نشط الذهن في فهم دلالاتحا ومعانيها،ويساعد في استيعاها وفهمها، والانتباه يعد المدخل الرئيس للاستفادة مما يقدمه المعلم 
من شرح، وما تقدمه الوسيلة التعليمية المصاحبة، فضلاً عن التعليمات التي تقدم للطلبة داخل الفصل وخارجه، بالإضافة المى دور الانتباه في أداء المهام الدراسية والامتحانات والاختبارات بمختلف أشكالها ولكي يكون الانتباه مثمرا، ومدخلا للمعرفة والتعامل مع المثيرات البيئية والاستفادة منها لصالح الانسان يتعين أن يتسم بالصفات الآتية: 2. 2. مدى استمرارية الانتباه. 1 1 انتقاء المثير. 4. تسلسل الانتباه بحسب مثيراته المعروضة. 3. 3 نقل الانتباه ومرونته.

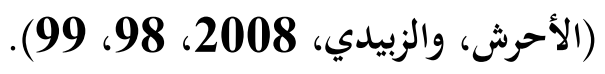

أنواع الانتباه: يمكن تقسيم الانتباه الى الأقسام التالية:

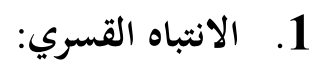

يعني الانتباه القسري أن الفرد يوجه انتباهه إلى المثير رغم ارادته، فالفرد عادة ينتبه رغم

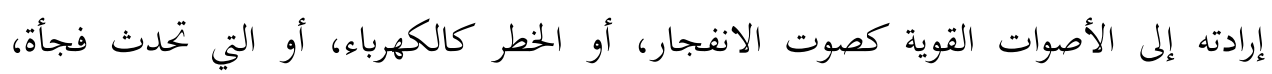

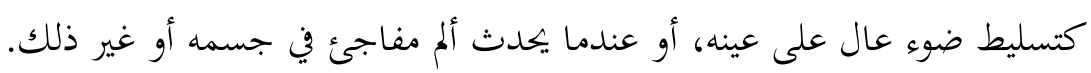
2. 2

الإنسان في العادة ينتبه إلى الأشياء التي تقع ضمن اهتمامه وميوله، فالموسيقى مثلا ينتبه فيها إلى ترتيب النغمات التي تصدر عن غيره، لذا فإن هذا النوع من الانتباه لايبذل فيه الفرد جهدا يذكر؛ لأنه يقع ضمن اهتمامه وميوله. 3. - 3. الانتباه الإرادي:

يقصد بالانتباه الإرادي أن يوجه الفرد انتباهه إلى شيء أو موضوع ما مثل الانتباه إلى محاضرة قد لايكون راغباً في الانتباه إليها، لذا فإنه يشعر بالملل والسأم ويبذل في ذلك الك الانتباه إنباه

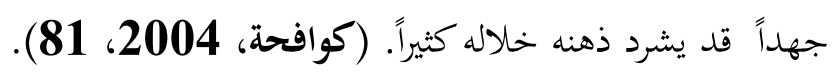
أسباب اضطرابات الانتباه: يرجع اضطراب الانتباه إلى عدة أسباب منها: 


\section{1. الأسباب المتعلقة بالمخ وتتمثل أعراضها فيما يأي:}

أ. حلل في وظائف المخ: إن عملية انتباه الفرد لمنبه معين تنقسم الى عدد من عمليات

الانتباه الأولية، وهي التعرف على مصدر التنبيه، وتوجيه الإحساس للمنبه، ثم تركيز الانتباه عليه،

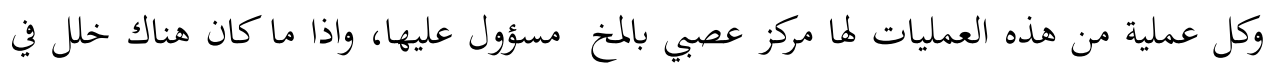
وظائف أحد هذه المراكز العصبية فإن المعلومات التي يعالجها ستصبح مشوشة وغير واضحة، مناك وبالتالي فإن انتباه الفرد يصبح مضطربا.

\section{ب. بأتأملات العصبية:}

وهي عبارة عن قواعد كيميائية تعمل على نقل الإشارات العصبية بين المراكز العصبية

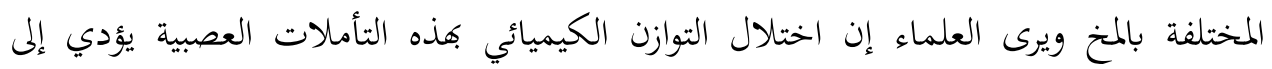
اضطراب ميكانيزم الانتباه.

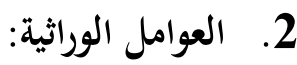

تلعب العوامل الوراثية دوراً مهماً في حدوث اضطراب الانتباه وذلك إما بطريقة مباشرة من خلال نقل الموروثات أو بضعف المراكز العصبية المسؤولة عن الانتباه بالمخ، أو بطريقة غير بهرب مباشرة من خلال نقل هذه الموروثات لعيوب تكوينية تؤدي إلى تلف أنسجة المخ. 3.

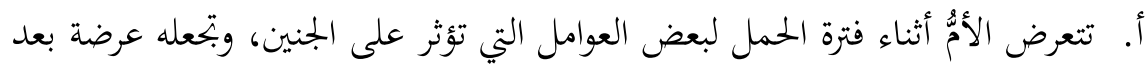

$$
\text { الولادة باضطراب الانتباه. }
$$

ب. قد تحدث في أثناء عملية الولادة بعض العوامل التي تسبب إصابة في مخ الجنين وتلف بعض خلاياه، مما يؤدي إلى ضعف قدرة المخخ على معالجة المعلومات.

\section{4. - بـ العوامل المتعلقة بالتغذية:}

إنَّ تناول الطفل لكميات كبيرة من الأطعمة الجاهزة، أو الخضروات والفواكه الملوثة بالمبيدات الحشرية، تؤدي إلى إصابته باضطراب الانتباه. 
5. العوامل المتعلقة بالعلاقة بين الطفل ووالديه:

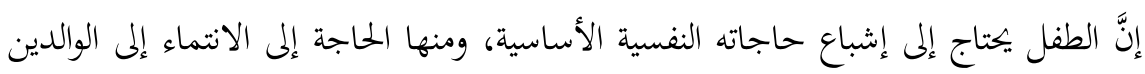
والحاجة إلى الحب، وتقدير واحترام الذات، ولذلك فإن أساليب المعاملة الوالدية الصحيحة تؤدي إلى إلى توافقه النفسي والاجتماعي. (الأحرش، والزبيدي، 2008، 105-107). تصنيفات العجز في الانتباه: لقد وضعت جمعية الطب النفسي الأمريكية سنة 1980م نمطين من أنماط العجز في الانتباه هما: 1 . العجز في الانتباه المصحوب بحركة زائدة.

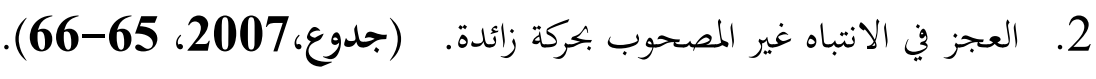
العوامل التي تساعد على إثارة الانتباه: بعض هذه العوامل داخلية أي شخصية خاصة بالفرد، والبعض الآخر عوامل خارجية أي موضوعية خاصة بالمنبه. 1. العوامل الداخلية: وهي ظروف دافعة تؤثر في ابتاه الانتباه، وتخضع للضبط الإرادي.

$$
\text { ومن هذه العوامل ما هو مؤقت مثل: }
$$

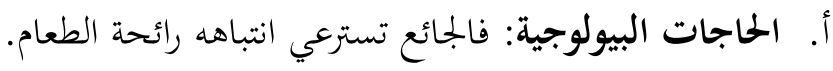

ب. التهيؤ الذهني: كانتظار قدوم شخص يهمك أمره، ويهيئ الذهن لاستقبال منبهات معينة بالذات فيسترعي انتباهك مثل: أصوات الأقدام، أو رنة جرس الباب والأم المستغرقة في النوم ليلا، لايوقظها قصف الرعد والمدافع بينما تستيقظ إذا بدرت من طفلها حركة بسيطة أو صوت ضئيل. ج. الاهتمام: من أهم العوامل التي تساعد على حصر الانتباه إلى موضوع معين هو

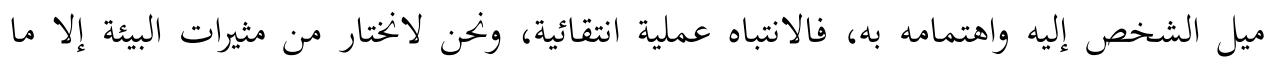
يتفق مع اهتماماتنا ثم نوجه شعورنا إليه أو نركز شعورنا فيه، وبالتالي فإن الانتباه والاهتمام 
مظهران لشيء واحد، فالاهتمام عبارة عن انتباه كامن بينما الانتباه هو اهتمام ناشط ومن

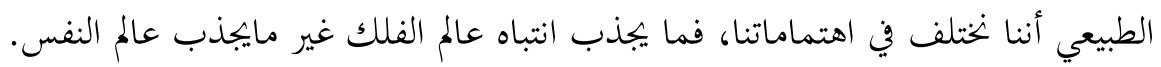
د. الايحاءات من الآخرين: القابلية للإيحاء قد تؤثر في توجيه الانتباه لموضوعات

معينة.

2. العوامل الخارجية: يستغل مصممو الاعلانات هذه العوامل في جذب انتباه الناس ومنها ما يلي: شدة المنبه: كاستخدام الميكروفون حتى يرفع صوت المعلن عما عداه من أصوات أو استخدام الأضواء الملونة البراقة الخ. تكرار المنبه: كمحاولة لجذب الانتباه.

التغير الفجائي للمنبه: في اللون أو الحجم أو الشدة أو الموضع.... الخ.

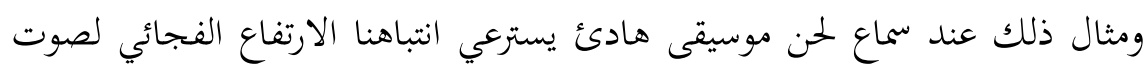

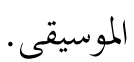
- - مركة المنبه: وهي نوع من التغير. - - التناقض: أي اختلاف المثير عما حوله. - - موضع المنبه: جذب الانتباه يتأثر بموضع المنبه بالنسبة لمجال الادراك.

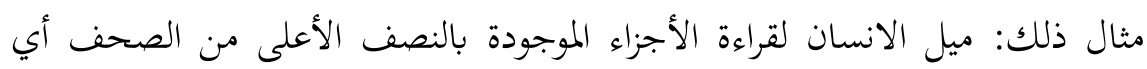

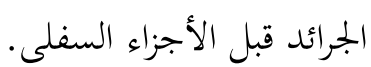

جميع هذه العوامل يتضح تأثيرها في الاعلانات الضوئية الكهربية المتحركة. (المليجي،

. $71-70$ 2004

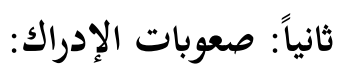

اتضح فيما سبق أن الانتباه هو العملية العقلية الأولى التي تمهد للإدراك، ووجود صعوبات في الانتباه يؤدي إلى قصور نمائي في عمليات الإدراك خاصة البصري، وهذا بدوره يؤثر 
سلباً على اكتساب التلميذ لمتطلبات الإدراك الضرورية للتحصيل باعتبار هؤلاء التلاميذ يواجهون صعوبة تحديد تفصيلات ما يواجه من مثيرات، والتمييز فيما بينها.

$$
\text { 1 شروط حدوث عملية الإدراك: حتى يتم الإدراك لابد من توافر شروط محددة. }
$$

يستخدم الإنسان في العادة حواسه المتعددة للتعرف على الأشياء فالطفل الصغير عندما

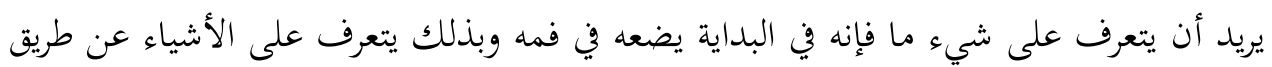

$$
\begin{aligned}
& \text { الذوق، ثم يندرج حتى يصل إلى استخدام العلاقات المترابطة. } \\
& \text { 2. وجود ما نود ادراكه: }
\end{aligned}
$$

لو نظرنا إلى العالم الخارجي لوجدنا أن هذا العالم ملئ بالأشياء والمواضيع، كل واحد

فيها يختلف عن الآخر، أي: تتمايز هذه المواضيع والأشياء عن بعضها البعض، فكل شيء لهاء له لهاء

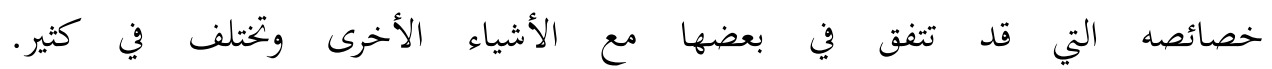

$$
\text { (كوافحة، 2004، 101-102). }
$$

$$
\begin{aligned}
& \text { 1. يعاني من صعوبة في تنظيم المثيرات البصرية وتفسيرها. } \\
& \text { 2. يجد صعوبة في التمييز البصري. } \\
& \text { 3. يخطئ في كتابة الأرقام حيث يكتبها معكوسة. } \\
& \text { 4. غالبا ما يخلط بين الحروف المتشابهة. } \\
& \text { 5. غير قادر على التمبيز السمعي. } \\
& \text { 6. يواجه مشكلة في اتباع سلسلة من التعليمات. } \\
& \text { 7. غير قادر على تفسير المثيرات السمعية. }
\end{aligned}
$$

8. ميجد مشكلة في تحقيق التناسق والتآزر البصري الحركي السمعي. ( مُحَّة، 2005، 
العوامل المؤثرة في الإدراك: هناك العديد من العوامل التي تؤثر في الادراك من بينها:

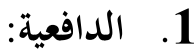

هي القوة النشطة التي تعد حصيلة قوى داخلية وقوى خارجية، وتكون وراء كل ما يفعله الانسان لذلك يمكن القول بشكل عام أن الأكثر دافعية أفضل إدراكاً. 2. 2. الحخبرة السابقة: إنَّ للخبرة السابقة أثرا في عملية الإدراك، فالخبرات الحياتية التي يكتسبها الفرد تساعده على إدراك المزيد.

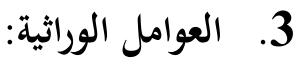

يتأثر النمو الإدراكي إلى حد كبير بالعوامل الوراثية من مادية ومعنوية فالسلامة الجسدية

$$
\text { والحسية تساعد على الادراك كما ينبغي. }
$$

ما دام الإدراك انتقائيا فهو يتأثر إلى حد ما بعواطفنا وميولنا فنحن ندرك الأشياء التي تستهوينا

بشكل أسرع من تلك التي لاتستهوينا. ( الأحرش،والزبيدي، إلـ 2008، 135-136).

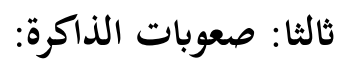

تعريف الذاكرة: هي وحدة من وحدات معالجة المعلومات التي يتم بها تسجيل وحفظ

$$
\text { واسترجاع الخبرة الماضية. ( ملحم، 2002، 260). }
$$

تعريف التذكر: هو قدرة الفرد على تنظيم الخبرات المتعلمة، وتخزينها ثم استدعائها أو

التعرف عليها والاستفادة منها في مواقف معينة.(الأحرش، والزبيدي، 2008، 145). أهمية العمليات التي تحدث في الذاكرة:

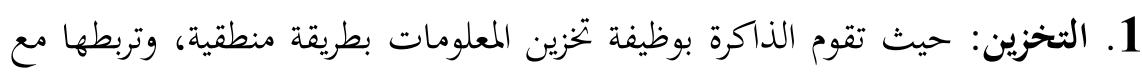
بعضها البعض من خلال عمليات التحديد والتمييز والتسلسل للمعلومات. 2. الاستزجاع ( الاستدعاء): حيث يقوم الفرد في هذه العملية باستدعاء المعلومات التي سبق تخزينها في حال غياها. 
3. التعرف:حيث يقوم الفرد في هذه العملية باختيار مثير محدد سبق أن تعلمه من بين

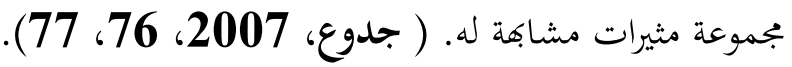

$$
\begin{aligned}
& \text { أهمية التذكر: تكمن أهمية التذكر فيما يأتي: }
\end{aligned}
$$

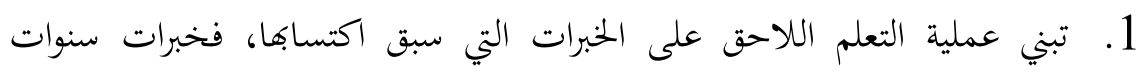

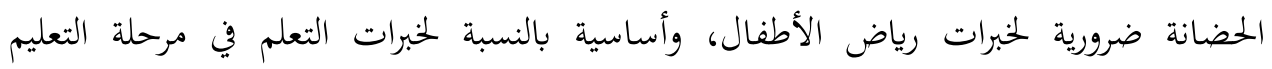
الأساسي تمهيداً لخبرات التعليم الثانوي والجامعي. 2. لا يمكن التعامل مع مواقف الحياة العملية من دون الاستفادة مما تعلم الفرد، فالإنسان يتعلم ليعيش ويتوافق مع البيئة الداخلية والخارجية عن طريق استعادة الخبرات المتعلمة وتطبيقها في الحياة.

3. يعتمد الابتكار وايجاد حلول جديدة للمشكلات التي تواجهنا على التذكر، لأن من طبيعة الخبرات المتعلمة أها تراكمية، وفي عصر التخصص والانفجار المعريف وثورة المعلومات لا يمكن للباحث أو العالم أو المصلح الاجتماعي أن يبتكر إلا باعتماده على إلى الخبرات التي سبق له أن اكتسبها في مجال معين من مجالات المعرفة والحياة.

(الأحرش، الزبيدي، 2008، 148)

أنواع الذاكرة: يمكن تحديد أنواع الذاكرة على وفق الآتي:

\section{1 الذاكرة العينية الحسية:}

وهي الذاكرة التي تتعلق بالانطباعات المتجمعة عن الطبيعة والحياة من خلال أعضاء

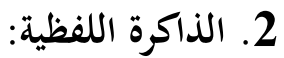

مضمون هذه الذاكرة هو افكارنا عن جوهر الأشياء وظواهرها، لكن الفكرة لاتوجد

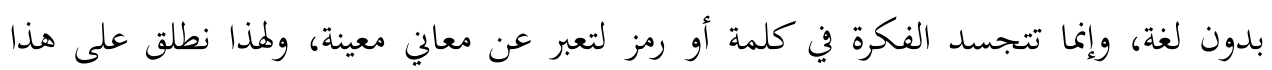
النوع من الذاكرة (المعاني)، حيث تكون غنية بنظام المفاهيم التي تجرد علاقات منطقية بين الظواهر أو الأشياء. 


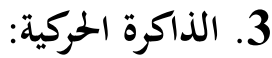

وهي ذاكرة اكتساب نماذج الحركة وحفظها واستدعائها التصورات العضلية الحركية،

لشكل الحركة وسرعتها ومقدراتا وسعتها وتتابعها وتيرتا وايقاعها.

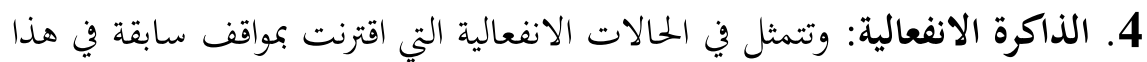

النوع من الذاكرة ويترجع الفرد الماضي مصحوبا بانفعالات معينة ايجابية وسلبية كشعورك بالخوف

$$
\text { ازاء مثير معين. ( ملحم، 2002، 265-266). أنواع الذاكرة حسب المدى المردي: }
$$

أ. الذاكرة قصيرة المدى: وهي التي تعتمد على الاستدعاء الفوري المباشر للخبرة

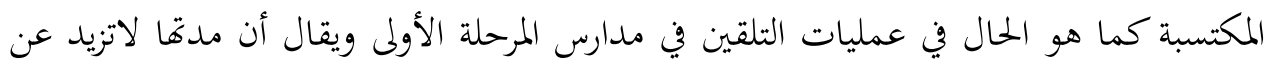

ب. الذاكرة طويلة المدى: وهي تعتمد على تنظيم الخبرات المكتسبة، وفق مبادئ معينة،

$$
\text { 6ما هو الحال في تذكر المقررات الدراسية وغيرها. }
$$

أ. الذاكرة القائمة على الحفظ الصم: كما هو الحال في تذكر الأمثال والأشعار، وسور

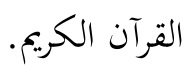

ب. الذاكرة القائمة على المعنى: وتستند في استرجاعها للخبرات إلى الربط بينها وإدراك المبادئ العامة التي تنظمها، كما في استعادة الموضوعات العملية في مختلف فروع المعرفة. علاج صعوبات التذكر:

1. الربط: وهي استراتيجية تساعد الفرد على تذكر المعلومة أو المعلومات عندما تربط بحدث معين أو تاريخ معين، أو اسم معين مثلا عندما نربط القاف في قابيل للتذكر من قبل

$$
\text { الآخر هو (هابيل) أو قابيل؟ لكابن }
$$

2. التكرار: إنَّ التكرار المستمر يساعد على طبع المعلومات في الذاكرة وبقائها حية في

الذهن ويسترجعها الفرد متى أراد ذلك، وهو أسلوب يتبع لمراعاة الفروق الفردية بين المتعلمين. 
3. استراتيجية التجميع: يكون التجميع إما عن طريق حروف أو أرقام في وحدات

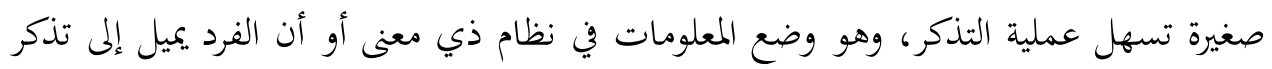
الأشياء التي تتسم بأفا منظمة متناسقة. 4. استراتيجية الكلمة المفتاحية: تعتمد هذه الاستراتيجية على اختيار كلمة أو كلمات تكون بمثابة مفتاح لتذكر المعلومة، وخاصة في مواد اللغات والشعر. 5. استراتيجية الحرف الأول: وهي بناء كلمات ذات معنى من الحروف الأولى لكل

كلمة أو جملة أو بيت من الشعر لتذكرها. (الأحرش، الزبيدي، 2008، 148، 154). المبادئ التي يجب أن يراعيها المعلم أثناء تدريس ذوي صعوبات التعلم النمائية هي:

$$
\begin{aligned}
& \text { 1. التدرج في عرض المعلومة. } \\
& \text { 2. تكرار عرض المعلومة. } \\
& \text { 3. الربط بين المعلومات. }
\end{aligned}
$$

4. إثارة الانتباه وحفز الدافعية طوال فترة الدرس.

$$
\text { - الخور الثالي: التقنيات التربوية }
$$

تتعدد المعاني والدلالات المعطاة لمصطلح الوسائل التعليمية في الأدب التربوي، فلا

يوجد اتفاق حول تعريف محدد لمذا المصطلح، اذثمة روئ مختلفة مطروحة في هذا الشأن.

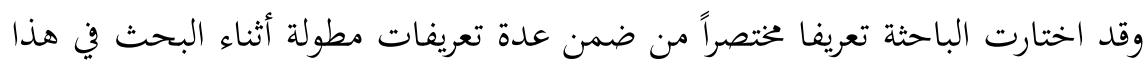

الموضوع، وينص هذا التعريف للتقنيات التربوية كما يأتي: مجموعة المواقف والمواد والأجهزة التعليمية والأشخاص الذين يتم توظيفهم ضمن

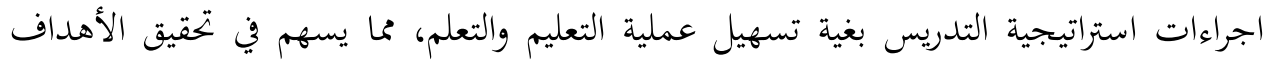
التدريسية الموجودة في هاية المطاف. http://www.gulfkids.com/ar/indexphp?action=www.show_art\&artc at $=18 \& \mathrm{id}=793$ 


\section{تكنولوجيا التعليم والتقنيات التربوية:}

مصطلح تكنولوجيا التعليم Instructional Technology في أصله مصطلح مُعرب أي: تم تعريبه وإدخاله إلى اللغة العربية، ومرادف هذا المصطلح في اللغة العربية هو "تقنيات التعليم" أو التقنيات التعليمية، ومن هذا المصطلح لكلمة التكنولوجيا يتضح أهنا ترتبط ارتباطاً وثيقاً بالعلم التقني، والدليل على ذلك في أصل الكلمة باللغة الانجليزية وهو Technique الذي يعنى تقنية أو تقانه، كما يتضح في إجماع العديد من التعريفات على أن كلمة تكنولوجيا تعنى الدراسة العلمية التطبيقية. (السعود، 2008، 21 21).

تعرف التقنيات التعليمية الخاصة لذوي الاحتياجات الخاصة Assistive Technology معدل أو مصنوع وفقاً للطلب بهدف زيادة الكفاءة العلمية والوظيفية لذوي الاحتياجات

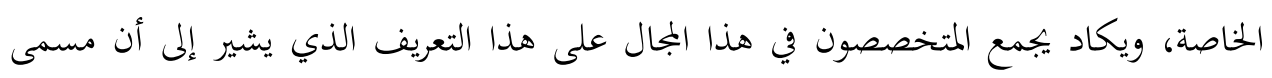

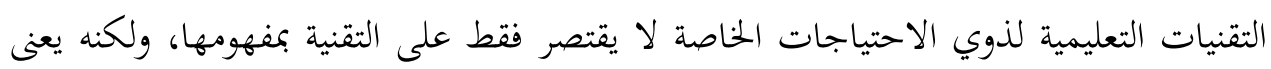

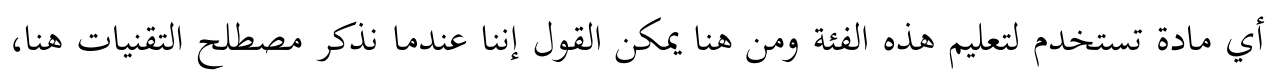
فليس المقصود بها فقط الأجهزة والالكترونيات، وإنما يقصد بها أي وسيلة تعليمية تساعد في تسهيل فهم المادة العلمية، حتى إن كانت السبورة أو الطباشير والكتاب والتي تعتبر أدوات تعليمية مساعدة.

\section{أنواع التقنيات التربوية لذوي الاحتياجات الحخاصة:}

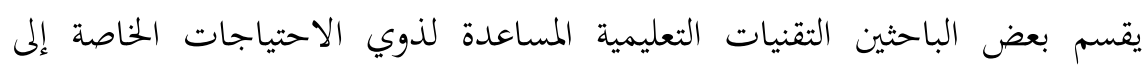
قسمين رئيسين هما:

1. التقنيات الالكترونية Electronic Tech: ومن أمثلتها الحاسب الألي وبرامجه

Data المختلفة، والتلفزيون التعليمي، والفيديو، ومسجل الكاسيت، وجهاز عرض البيانات Show والآلة الحاسبة وغيرها من الأجهزة الكهربائية والالكترونية. 
2. السبورة،والكتاب والصور، والمجسمات، وغيرها من الوسائل غير الكهربائية أو الالكترونية.

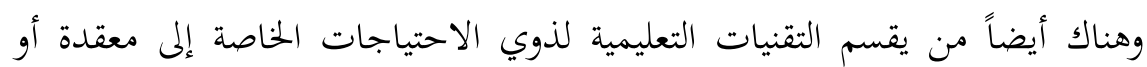
شديدة التعقيد، وتقنيات متوسطة، وأخرى بسيطة أو سهلة الاستخدام.

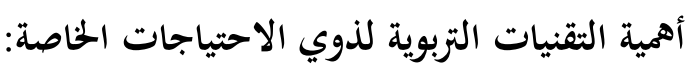
إن استخدام التقنيات التربوية في حياة التلاميذ ذوي الاحتياجات الخاصة لها العديد من

$$
\text { الفوائد التي تعود عليهم من عدة نواحي منها: }
$$

أتبتث دراسات علمية عديدة ومنها دراسة الجهني، والزراع (2014) ودراسة العصيمي( 2015) أن لاستخدام الحاسب الألى مثلاً دور كبير في خفض التوتر والانفعالات لدى التلاميذ، حيث تتوفر برجيات Software فيها الكثير من البرامج المسلية والالعاب الجميلة التي تدخل البهجة والسرور في نفوس هؤلاء التلاميذ، كما تخفف من حدة التوتر والقلق النفسي تئي لديهم، كما يستخدم كثير من المعلمين الوسيلة كمعزز إيجابي أو سلبي في تعديل سلوك الأطفال ذوي الاحتياجات الخاصة.

\section{ثانيا: من الناحية الأكاديمية:}

يؤدي استخدام التقنيات التعليمية إلى تسهيل نقل وشرح المعلومة للتلاميذ ذوي الاحتياجات الخاصة والمساعدة في رفع مستواهم الأكاديمي. ثالثاً: من الناحية الاجتماعية:

إنَّ استخدام بعض التقنيات كالحاسوب ساعد كثيراً في تكوين صداقات عديدة بين التلاميذ عندما يعملون كمجموعات أو يتبادلون الخبرات والمعلومات بينهم، أي أن التقنيات ساهمت في خروجهم من العزلة والانطوائية، ونمت فيهم روح العمل الجماعي وحب المشاركة وعلَّتهم كثيرا من القيم الاجتماعية من خلال احتكاكهم وتفاعلهم مع غيرهم من الأطفال. http://www.tgnyat.blogspot.com.12012\12 blogpost_5054.hTml. 
بالإضافة إلى ذلك إن استخدام التقنيات التربوية يساعد التلاميذ في التخلص من التشتت

وتزيد من فترة الانتباه لديهم وبخاصة ذوي صعوبات التعلم. (سلامة، أبوريا، 2002). دور المعلم في استثمار التقنيات التربوية لتعليم ذوي صعوبات التعلم النمائية: إن المدرس الجيد يجب أن يختار التقنيات التربوية المناسبة التي تتماشى مع الحقائق العلمية التي يريد توصيلها للتلاميذ ذوي صعوبات التعلم النمائية، التي من خلالها يتضح الاختلاف في مدى وسعة الانتباه بين التلاميذ في المدارس بين المراحل الدراسية المختلفة (ابتدائية -ثانوية)، وبالتالي يوفر فرصاً للتعلم، كما يتوجب استخدام تقنيات تربوية متنوعة ومناسبة لكي

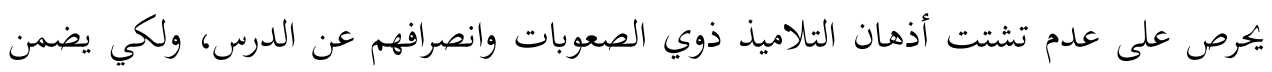

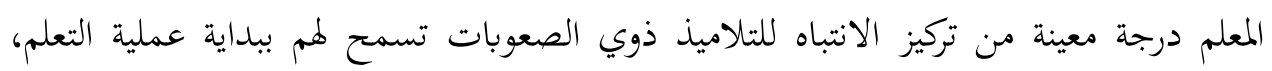

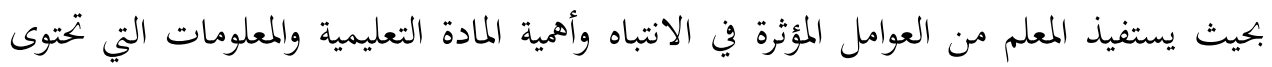
عليها، وطريقة عرضها وتنوع أساليب الشرح أو الإلقاء، يجب على المعلم ربط المادة العلمية

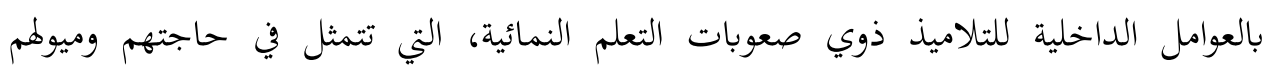
وتوقعاقم.

\section{الأشياء التي ينبغي أن يلزم المعلم التلاميذ بما منها:}

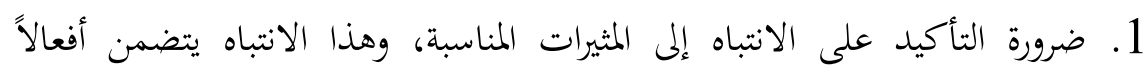
لا يمكن ملاحظتها كالنظر إلى المعلم، والإصغاء لما يقال، أو قد يتكون من أنشطة كتفكير التباه التلميذ في الموضوع الذي يكلف بتعلمه.

2. على المعلم استثمار المثيرات التي بجذب انتباه التلميذ ذوي صعوبات تعلم نمائية

$$
\text { والتي تستحوذ على اهتمامه. }
$$

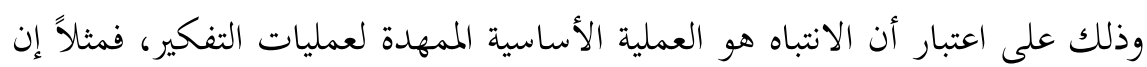

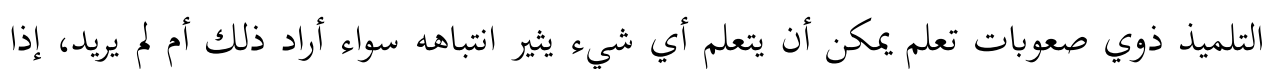

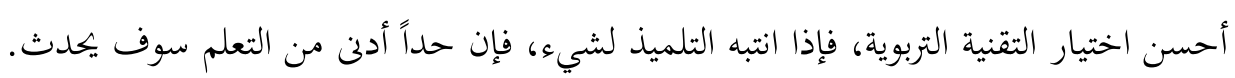


وتستنتج الباحثة مما سبق أن المعلم يستطيع أن يحدد أوجه النشاط المناسب لتدريس موضوع معين، ويقبل التلميذ على النشاط الذي يشترك في اختياره، ولذلك فإنه يفضل ألا يعتمد المعلم على خبرته وحدها في اختيار النشاط الذي يوجه إليه تلاميذه، بل الأفضل أن يشرك

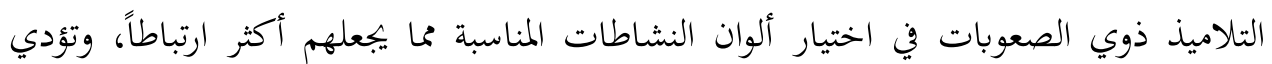
مشاركة التلاميذ إلى الاستفادة من التقنيات التربوية وجعل عملية التعلم شيقة يقبل عليها التلاميذ من تلقاء أنفسهم.

\section{- الخور الثالث: الدراسات السابقة:}

إن الاطلاع على الدراسات السابقة أمر هام ومفيد عند إجراء أي دراسة يقوم بها الباحث، وخاصة إذا كانت لها صلة بموضوع الورقة البحثية المراد البحث عنها إذ من خلالها يتعرف الباحث على دور التقنيات التربوية في تعليم ذوي صعوبات التعلم النمائية، التي أشارت لها تلك الدراسات، وطرق علاجها والأهداف التي سعت لتحقيقها، والعينات، والأساليب الأحصائية، وطرق عرض وتفسير النتائج.

$$
\text { أولاً: عرض الدراسات السابقة: }
$$

\section{1. دراسة عبد العزيز بن مُحمَّم العصيمي (2015):}

هدفت الدراسة إلى الكشف عن واقع استخدام التقنيات التعليمية الحميثة في غرفة المصادر والصعوبات التي يواجها معلمي ذوي صعوبات التعلم،وتكونت عينة الدراسة من (84) معلم ذوي صعوبات التعلم من مجتمع الدراسة، واستخدمت الدراسة المنهج الوصفي التحليلي، واستخرجت الثبات بطريقة ألفاكرونباخ وقد تم استخدام مجموعة من من الأساليب الأحصائية لتحليل البيانات، وتوصلت الدراسة إلى النتائج الآتية: 1. هناك فروق ذات دلالة إحصائية بين متوسطات استجابات معلمي التلاميذ ذوي صعوبات التعلم حول استخدام التقنيات التعليمية تعود لمتغير سنوات الخبرة. 2. هناك فروق ذات دلالة إحصائية بين متوسطات استجابات معلمي التلاميذ ذوي صعوبات التعلم حول استخدام التقنيات التعليمية تعود لمتغير الدورات التدريبية. 
3. هناك فروق ذات دلالة إحصائية بين متوسطات استجابات معلمي التلاميذ ذوي

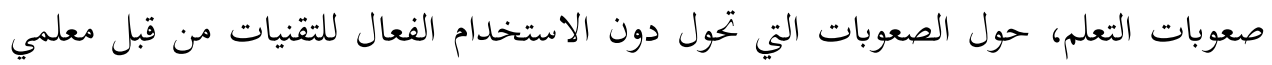
ذوي صعوبات التعلم، وتعزى لمتغير الدورات التدريبة، وذلك لصالح غير الحاصلين على دورات تدريبية في بجال تقنيات التعليم.

\section{2. دراسة عبد اللطيف (2010):}

برنامج مقترح لعلاج معوقات استخدام التقنيات التعليمية في برامج صعوبات التعلم بالمرحلة الابتدائية في مدينة الرياض، حيث استخدم المنهج الوصفي، وكان عدد العينة العشوائية من معلمي صعوبات التعلم في مدينة الرياض(180) معلماً، وتوصلت الدراسة إلى النتائج الآتية: 1. إنَّ أكثر التقنيات توافرًا واستخدامًا هي ( جهاز الحاسب الآلي، الطابعة، أقلام سبورة، السبورة المغناطسية،آلة تصوير ورقية، برامج لإدارة الأعمال الكتابية ).

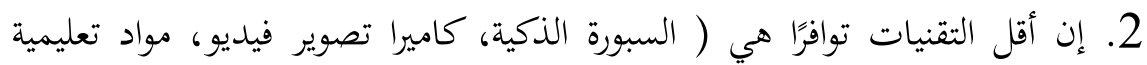

$$
\text { صوتية،جهاز عرض الفيديو الرقمي، اسطوانات تعليمية ). }
$$

3. إن التقنيات الأقل استخداماً هي (جهاز التسجيل الصوتي، جهاز التلفاز، جهاز

$$
\text { العرض فوق الرأس، كاميرا تصوير فيديو، جهاز السبورة الذكية). }
$$

4. إن أكثر التقنيات التعليمية أهمية هي( جهاز الحاسب الألي، برامج لإدارة الأعمال

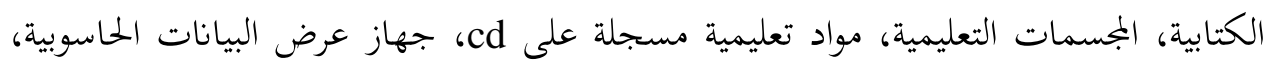
أقلام سبورة ملونة، جهاز السبورة الذكية. 5. إن أهم الاعاقات التي تحد من استخدام التقنيات التعليمية هي: كثرة الأعمال الكتابية، وتأخر استلام التقنيات التعليمية، وارتفاع تكاليف المواد الخام، وعدم توافر البرجيات التعليمية. 


\section{3. دراسة قرشم وحسين (2010):}

وهذه الدراسة هدفت إلى تقديم برنامج مقترح لعلاج صعوبات تعلم الرياضيات لدى تلاميذ المرحلة المتوسطة في ضوء مستحدثات تقنيات التعليم، حيث استخدم الباحثان المنهج الوصفي وتكونت عينة الدراسة من (392) تلميذاً بالصف الأول المتوسط في مدينة الطائف وتوصلت النتائج إلى: تحديد نسبة شيوع صعوبات تعلم الرياضيات لدى تلاميذ(17.86\%) بعد تطبيق محكات التباعد والخصائص السلوكية والاستبعاد، وأن أهم جوانب صعوبات التبع التعلم تمثلت في العمليات المركبة والمفردات.

\section{4- دراسة الشيباني (2004):}

هدفت إلى تحديد الحاجات التدريبية لمعلمي صعوبات التعلم من وجهة نظر أعضاء هيئة التدريس بقسمي تكنتولوجيا التعليم والتربية الخاصة، ومشرفي ومعلمي صعوبات التعلم،

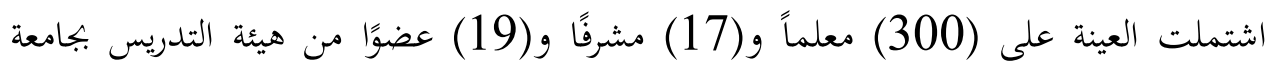
الملك سعود وتوصلت إلى النتائج الآتية: 1. وجود مستوى من القناعة جيد لدى معلمي التلاميذ ذوي صعوبات التعلم والمشرفين التربويين بأهمية استخدام التقنيات التعليمية بأنواعها المختلفة.

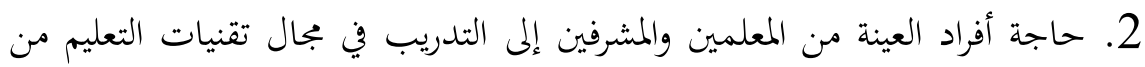
أجل التخطيط للدروس وتنفيذها. 3. قلة توفر بعض التقنيات التعليمية والبرامج الخاصة لاستخدامها أثناء التدريس. 5- دراسة ماك آرثر، وتشارلز، وفيريتى، وورالفز، واكولو، وسانثيا

\section{(MacArthur,Charles ferretti,Ralph,Okolo,Cynthia,2001} هدفت دراستهم إلى معرفة مدى استخدام معلمي التلاميذ ذوي صعوبات التعلم للتقنيات التعليمية، أثناء تعليم التلاميذ القراءة والكتابة، والتعرف على ابتاهاتم نهوها، ومدى إنى استفادقم منها في عملهم مع التلاميذ وفي عملهم داخل غرفة المصادر، تكونت عينة الدراسة من حوالي (1000) معلم من ولاية Delaware وتوصلت إلى النتائج الآتية: 
1. يرى المعلمون أن التقنيات التعليمية أداة فعالة لتعليم التلاميذ ذوي صعوبات القراءة والكتابة. 2. أظهر حوالي 97\% من المعلمين أفم يرون أن التقنيات التعليمية تساعد التلاميذ على اكتساب مهارات القراءة والكتابة والتعرف على الكلمات، وتصحيح الأخطاء وبتحب لمبن الوقوع فيها. 3. يرى المعلمون أن استخدام الحاسب الآلي من التقنيات التي تساعدهم على تقديم ممارسة أطول للتلاميذ، ومراقبة وسرعة ودقة على استجابات التلاميذ. ثانيًا: مناقشة الدراسات السابقة: يتضح من عرض الدراسات السابقة أها تختلف باختلاف البيئات التي أجريت فيها الدراسة، وأيضاً تختلف باختلاف نتائجها، وفيما يلي أوجه الشبه والاختلاف بين تلك الدراسات والورقة البحثية على النحو الآتي: 1. 1 - مدف الدراسة:

اختلفت الدراسات السابقة من حيث أهدافها، فقد هدفت دراسة عبد اللطيف (2010) إلى بناء برنامج مقترح لعلاج معوقات استخدام التقنيات التعليمية في برامج صعوبات التعلم بالمرحلة الابتدائية في مدينة الرياض، أما دراسة قرشم وحسين (2010) فهدفت إلى تقديم برنامج مقترح لعلاج صعوبات تعلم الرياضيات لدى تلاميذ المرحلة المتوسطة في ضوء

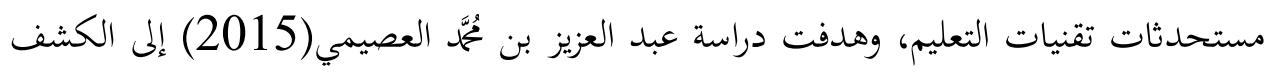
عن واقع استخدام التقنيات التعليمية الحديثة في غرفة المصادر والصعوبات التي يواجهها معلمي ذوي صعوبات التعلم، وبالنسبة إلى دراسة الشيباني (2004) فهدفت إلى تحديد الحاجات التدريبية لمعلمي صعوبات التعلم من وجهة نظر أعضاء هيئة التدريس بقسمي تكنتولوجيا التعليم والتربية الخاصة، ومشريف ومعلمي صعوبات التعلم، أما دراسة ماك آثثر وآخرون (2001) فهدفت إلى معرفة مدى استخدام معلمي التلاميذ ذوي صعوبات التعلم للتقنيات التعليمية، أثناء 
تعليم التلاميذ القراءة والكتابة، والتعرف على اتحاهاتم نحوها، ومدى استفادقم منها في عملهم مع التلاميذ وفي عملهم داخل غرفة المصادر. أما البحث الحالي فيهدف إلى تحديد آليات تفعيل التقنيات التربوية في تعليم ذوي

$$
\text { صعوبات التعلم النمائية. }
$$

اتفقت الدراسات السابقة فيما بينها من حيث مكان الدراسة فقد أجريت جميع الدراسات السابقة في السعودية، أما البحث الحالى فقد أجري في دولة ليبيا بمدينة مصراتة.

\section{3. - - 2 - مينة الدراسة:}

اتفقت بعض الدراسات السابقة فيما احتوته على المرحلة التعليمية، حيث طبقت بعضها على المرحلة الابتدائية كدراسة عبد العزيز العصيمي(2015)، ودراسة عبد اللطيف (2010)، وبالنسبة لدراسة ماك آرثر وآخرون (2001) فقد طبقت على المرحلة المتوسطة، أما دراسة الشيباني (2004) فقد أجريت على المرحلة الجامعية. أما البحث الحالي: فقد حددت الفئة العمرية تلاميذ المرحلة الابتدائية.

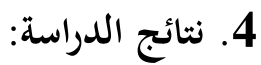

أكدت الدراسات السابقة في معظمها والتي تناولت واقع استخدام التقنيات التعليمية في

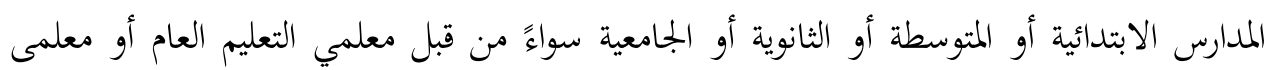
التربية الخاصة، وبالأخص معلمي التلاميذ ذوي صعوبات التعلم أن لها فاعلية كبيرة في مجال التعليم فهم أحوج ما يكون لمثل تلك التقنيات لانخفاض بعض القدرات لديهم أو فقدها والتى تسلتزم استخدام أكثر من قناة ووسيلة لايصال المعلومة لهم، كما أكدت نتائج الدراسات السابقة أن هناك قلة في البرامج التدريبة في مجال تقنيات التعليم، ووجود العديد من الصعوبات التي تعيق استخدام التقنيات التعليمية من قبل المعلمين داخل صفوفهم ومع تلاميذهم.

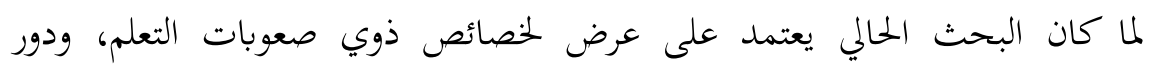
التقنيات التربوية في التغلب على بعض المشكلات التعليمية، فيمكن للباحثة أن تستنتج كيفية 
تفعيل هذه التقنيات في تعلم ذوي صعوبات التعلم النمائية آخذة في الاعتبار الخصائص والسمات المميزة لهذه الفئة، وذلك بعد عرض ومناقشة الدراسات السابقة. - الحور الرابع: آليات تفعيل التقنيات التربوية في علاج صعوبات التعلم النمائية فيما يلي تعرض الباحثة آليات تفعيل التقنيات التربوية لذوي صعوبات التعلم لكل صعوبة نمائية على حدة:

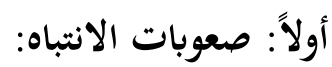

يمكن للمعلم باستخدامه للتقنيات التربوية أن تنشط انتباه التلاميذ للدرس من خلال:

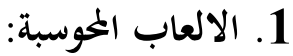

إن استخدام الألعاب بالكمبيوتر يعمل على إيجاد مناخ تعليمي يمتزج فيه التحصيل

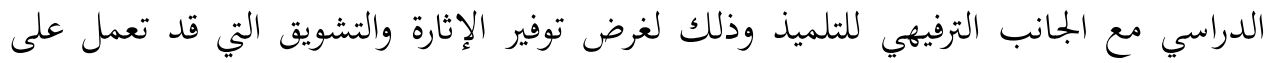
تحسين انتباه التلاميذ نحو تعلم الدرس، ويمكن أن نستفيد من الألعاب الكمبيوترية في تحقيق أهداف تعليمية أخرى مثل تعلم المفاهيم والمهارات. 2. المواقف التنافسية باستخدام الحاسوب:

يمكن للمعلم أن يستفيد من هذه التقنية التعليمية عن طريق تقديم موقف للتلاميذ، بحيث يسمح للتلاميذ بالتنافس ويكون بين تلميذين أو أكثر، وهذا البرنامج يمدد النقاط التي يأخذها كل تلميذ وبذلك نستطيع معرفة الفائز. 3. برامج المحاكاة والنمذجة بالحاسوب:

يمكن أن تستخدم في تقديم محاكاة للظواهر الطبيعية البسيطة المعقدة كما أنها تساعد التلميذ على التحكم في تنفيذ البرنامج، وزيادة دافعية للتعلم، وتنمية مهارات التلميذ في التحليل والتركيب والتقويم. 


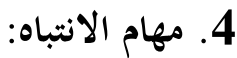

ويتم من خلال عرض أشكال أو صور لمدة معينة، ثم يتم إخفائها، ويطلب من المتعلم أن يذكر ما شاهده بالترتيب، ومن خلال عدد الصور أو الأشكال التي يتذكرها المتعلم يمكن تحديد سعة الانتباه ومداه.

يمكن استخدام الحاسوب في عرض هذه المهمات، فالحاسوب يسمح للمتعلم بالتحكم في وقت الاستجابة الذي يمضي بين عرض المادة التعليمية على الشاشة المتعلم وبين استجابته لما، وكذلك يسمح بتكرار المادة التعليمية، والسرعة التي تعرض بها المادة، وكمية المادة التي يتعلمها لماكيا المتعلم، والوقت الذي يجب أن يجلس فيه المتعلم أمام الكمبيوتر. 5.

يتم ذلك من خلال تدريب المتعلم على عمليات الترميز ( التشفير) حيث تعرض عليه

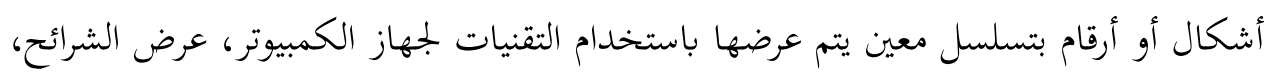

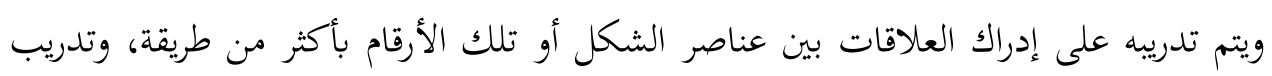

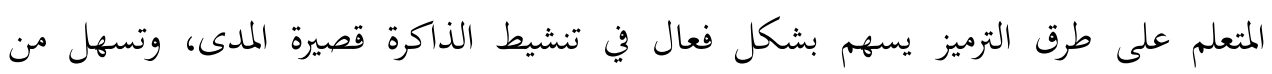

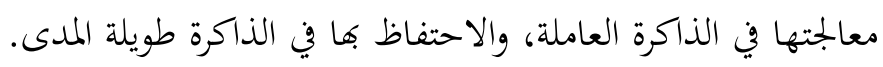

$$
\text { ثأ. ثناً: صعوبات الإدراك: }
$$

يمكن للمعلم تنمية الإدراك البصري للتلاميذ الذين يعانون من صعوبات تعلم نمائية

وذلك بالطرق الآتية: - م

\section{1. استخدام أقلام ملونة أثناء الكتابة على السبورة:}

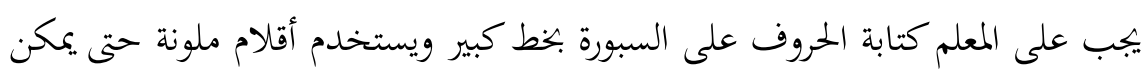

$$
\text { تمييز الحروف المتشاهمة. }
$$




\section{2. عمل ججسمات خاصة لتمييز الحروف المتشابكة:}

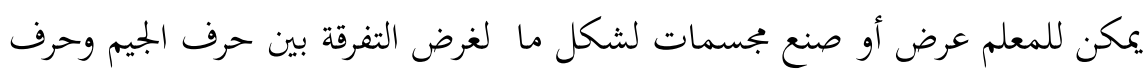
الخاء، فمثلاً يصنع مجسم لحيوان الجمل، وبجسم آخر يمثل شكل الخروف؛ وذلك ليتمكن التلميذ من التفرقة بين حرف الجيم وحرف الخاء من خلال المجسمات المعروضة أمام التلاميذ ذوي

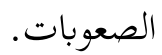

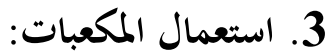

من خلال تدريب المعلم للتلاميذ على استخدام مكعبات مختلفة الألوان والأشكال سواء أكان من الخشب أو البلاستيك، لإنتاج أشكال أو نماذج مختلفة. 4. عرض تصميمات هندسية الشكل باستخدام الحاسوب: هنا يقوم المعلم باستخدام أو عرض تصميمات هندسية الشكل لرقم أو حرف، ويطلب من أحدهم اختيار التصميم المماثل من بين مجموعة من البدائل. 5. تنمية الإدراك البصري باستخدام الكمبيوتر:

يمكن للمعلم عن طريق استخدام الكمبيوتر أن يعمل على تنمية الإدراك البصري للتلاميذ من خلال عرض أشكال بينهم تتشابه إلى حد كبير، واختلاف في بعض التفاصيل على لئل الكمبيوتر، ويطلب المعلم من أحد التلاميذ تحديد أوجه الاختلاف، وفي كل محاولة منه يقوم التلميذ بتعزيزه بالصوت أو الحركة.

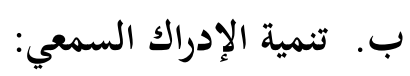

يمكن للمعلم أن يعمل على تنمية الادراك السمعي من خلال استخدام الآتي: 1. الكمبيوتر:عن طريق استخدام البرجيات المسموعة حتى يتمكن التلاميذ من تمييز أصوات الحروف بالحركات أو تمييز أصوات الأشخاص أو الحيوانات. 
2. استخدام المعلم لأنشطة وبرامج متنوعة داخل الفصل:

ذلك لتنمية الذاكرة السمعية والتتابع السمعي، ولكي يقوم التلميذ بذلك يستطيع المعلم

معرفة قدرة التلاميذ في الانتباه السمعي يمكنه أن يقدم نشاط لهؤلاء التلاميذ فمثلا يطلب منهم غلق أعينهم وتحديد الأصوات المختلفة التي يقوم المدرس بأدائها، فأحيانا يستخدم المدرس: -

وهذه الآليات جميعها تعتمد على التكرار، وزيادة المهام، وتنوعها مع وعاء زمنى مناسب.

ثالثاً: صعوبات أو اضطراب عمليات الذاكرة لذوي صعوبات التعلم النمائية: ويمكن ذلك من خلال الآتي:

\section{1. تدريب المتعلم على عمليات الترميز " التشفير":}

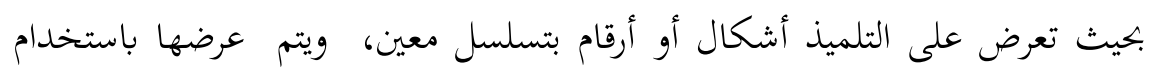
التقنيات كجهاز الكمبيوتر، عرض الشرائح، كما يتم تدريبه على إدراك العلاقات بين عناصر

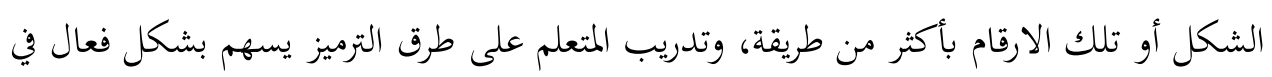

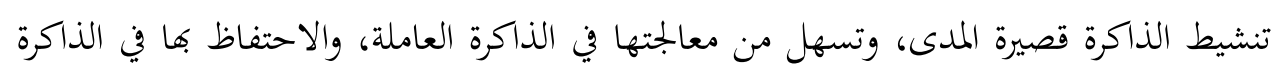
طويلة المدى.

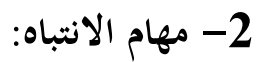

يقوم المعلم بتدريب التلاميذ ذوي صعوبات التعلم النمائية على مهام الانتباه بشكل مستمر؛ لحفز وتنشيط الانتباه، كأن يقوم المعلم بعرض سلسلة قصيرة من الأشكال أو الصور وفقاً لترتيب معين، ثم يطلب من أحد التلاميذ استرجاع هذه الاشكال أو الصور وفقاً للترتيب

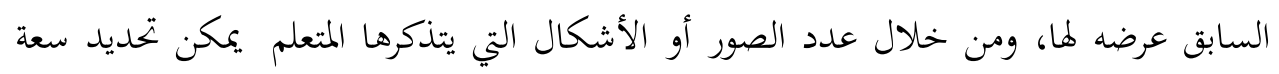

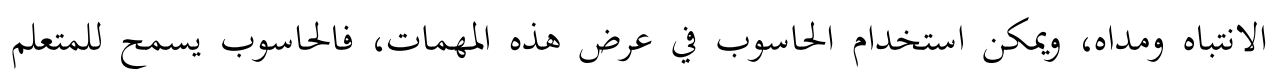


بالتحكم في وقت الاستجابة الذي يمضي بين عرض المادة التعليمية على الشاشة لمتعلم وبين استجابته لما، وكذلك يسمح بتكرار المادة التعليمية، والسرعة التي تعرض بها المادة، وكمية المادة التي يتعلمها المتعلم، والوقت الذي يجب أن يجلس فيه المتعلم أمام الكمبيوتر.

\section{3. استعمال المعلم للرسومات والأشكال التخطيطية ( خرائط المفاهيم):}

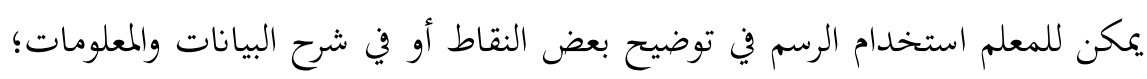

لكي يسهل تذكرها بالنسبة للتميذ، كما يساعد الرسم على تحسين ذاكرة التلاميذ، والاحتفاظ بها لفترة أطول، وكذلك تدريب ذوي صعوبات التعلم على بناء خرائط مفاهيمية لمحتوى المادة الدراسية، ومساعدة الطلاب على قراءقا، وحفز الانتباه إلى استكشاف العلاقات بين المفاهيم المتضمنة بها واتجاه العلاقة بينهما.

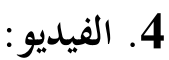

يلعب الفيديو دوراً كبيرا كعنصر من عناصر تقنيات التعلم، فهو يعطي التلاميذ إيحاء

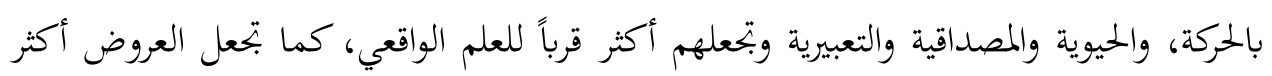
متعة وإثارة عند مشاهدتما واستخدامها.

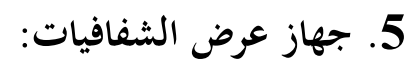

يعتبر هذا الجهاز من أكثر وسائل الاتصال التعليمية انتشاراً في المدارس محا يتيح للمعلم

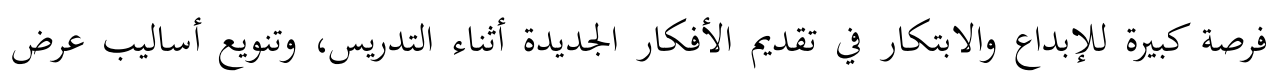

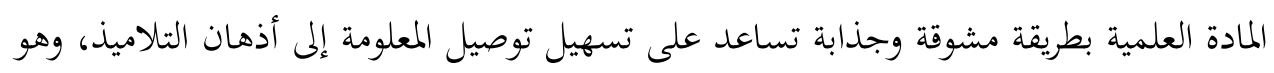
جهاز يحوى لوح من الزجاج الشفاف لوضع الشفافية المعدة عليه أو الورق الشفاف للكتابة عليه، وتقوم المرآة العاكسة بعكس الصورة على شاشة العرض. كما أن هناك تقنيات تربوية أخرى يمكن الاستفادة منها في تعليم ذوي صعوبات التعلم النمائية تتمثل في: - n 1 . - جهاز العرض فوق الرأس. 
2. اللوحات التعليمية ( الوبرية، الجيوب المغناطسية، الكهربائية، السبورة الذكية

$$
\begin{aligned}
& \text { التفاعليه "). } \\
& \text { 3. مسرحيات الدمى. } \\
& \text { توصيات البحث: }
\end{aligned}
$$

بعد اطلاع الباحثة على مجموعة من الكتب والدراسات السابقة التي تتحدثت عن هذا

$$
\text { الموضوع توصي الباحثة بالآتي: }
$$

1. توعية المعلمين بأهمية استخدام التقنيات التعليمية من خلال ورش العمل والندوات.

2. توفير برامج تدريبية للمعلمين على كيفية استخدام وإنتاج المواد التعليمية وتطويرها.

$$
\text { 3. توفير أجهزة تكنولوجيا التعليم والمعلومات في المدارس. }
$$$$
\text { 4. ضرورة عمل صيانة دورية لأجهزة تقنيات التعليم. }
$$

5. توفير الميزانيات المناسبة لشراء وإنتاج المواد التعليمية.

6. العمل على تفعيل مشاركة المعلمين مع المشرفين التربويين في تطوير المواد والتقنيات

$$
\text { التعليمية التي تتناسب مع الطلاب ذوي صعوبات التعلم. }
$$

7. زيادة الوقت المخصص للحصص بما يتناسب مع استخدام تقنيات التعليم.

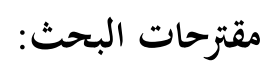

من خلال عرض الباحثة لمجموعة من التوصيات تقترح إجراء بحوث أو دراسات لاحقة

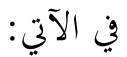

1. إجراء دراسة لمعرفة واقع التقنيات التعليمية في برامج صعوبات التعلم والصعوبات

$$
\text { التي تواجه معليمهم لاستخدامها. }
$$

2. إجراء دراسة حول كيفية الحد من الصعوبات التي تحول دون الاستخدام الفعال

$$
\text { للتقنيات التعليمية من قبل معلمي ذوي صعوبات التعلم. }
$$

3. إجراء دراسة لمعرفة الصعوبات التي تواجه المعلمين من وجهة نظر المشرفين التربويين. 


\section{الحاتمة}

لعل من أهم أهداف التقنيات التعليمية المساندة لذوي صعوبات التعلم النمائية، هو مساعدة هذه الفئة لتحقيق أقصى درجة من التكيف مع البيئة التعليمية والعملية والاجتماعية والاستقلالية، حتى تكفل لهم حياة سليمة أقرب ما تكون إلى الطبيعية.

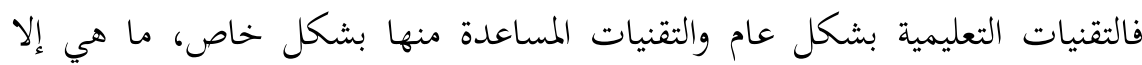
أدوات نتطلع من استخدامها إلى التخفيف من المشاكل التي يعاني منها ذوي صعوبات التعلم النمائية.

وبالرغم من ذلك يعتقد الكثير على وجه الخطأ أن التقنيات لوحدها هي حل لمشاكل

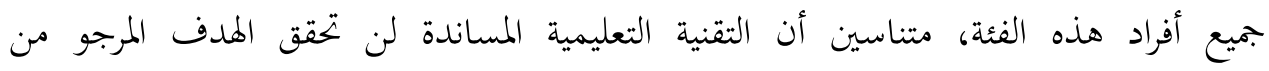
استخدامها إلا إذا كانت مناسبة لخصائص الفرد واحتياجاته وقدراته، ومن ثم استخدامها

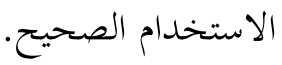

وبناءً على ذلك تقترح الباحثة أن يراعي المهتمون والمسؤولون عند استخدام التقنيات التعليمية لذوي صعوبات التعلم النمائية ما يأتي: 1. فهم نوع صعوبة التعلم ودرجتها بالتفصيل لمراعاة الاحتياجات الخاصة بهذه الفئة.

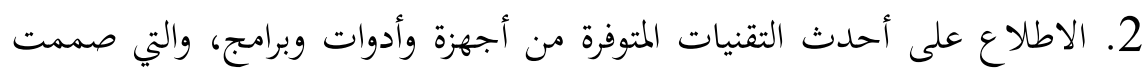
لاستخدام ذوي صعوبات التعلم.

3. فهم كامل لامكانيات وماهي الصعوبات التي خصصت لتخطيها. 4. توفير الدعم الفني المتواصل لتمكين الأفراد من الحصول على أكبر فائذة مما تقدمه لهم هذه التقنيات. 


\section{قائمة المراجع}

$$
\text { أولاً: المراجع العربية: }
$$

1- الأحرش، يوسف أبو القاسم، الزبيدي، يُمَّم شكر، (2008 ) صعوبات التعلم، ليبيا: دار الكتب الوطنية.

2- - جذوع، عصام، ( 2007 ) صعوبات التعلم، عمان: دار اليازوري العلمية للنشر والتوزيع. 3- الخطيب، جمال، (2005 ).استخدامات التكنولوجيا في التربية الخاصة، عمان: دار وائل للنشر والتوزيع.

4- الزبيدي، تُمَّمَ شكر، المدخل إلى الفئات الخخاصة، دار الكتب الوطنية، بنغازي، 2007. 5- الزيات، فتحي مصطفى، (2000)، صعوبات التعلم لدى طلاب المرحلة الجامعية افتراضات نظرية ونتائج ميدانية، القاهرة: دار النشر للجامعات، جـات 6- السعود، خالد عُمَّه،(2008)، تكنولوجيا ووسائل التعليم وفاعليتها، عمان: مكتبة المجتمع العربي للنشر والتوزيع. 7- سلامة، عبد الحافظ، أبوريا، يُمَّه، (2002)، الحاسوب في التعليم، عمان: الأهلية للنشر والتوزيع. 8- كوافحة، تيسير مفلح، (2004 )، علم النفس التربوي، عمان: دار المسيرة للنشر والتوزيع. 9- عُمَّ، عادل عبد الله،(2005)، قصور المهارات قبل الأكاديمية لأطفال الروضة، القاهرة: دار الرشاد. 10 - محمود، شوقي حساني، (2008)، تقنيات وتكنولوجيا التعليم، القاهرة: المجموعة العربية للتدريب والنشر.

11- ملحم، سامي يُمَّم، (2002)، صعوبات التعلم، عمان: دار المسيرة للنشر والتوزيع. 12- المليجي، حلمي، (2004 )، علم النفس المعرفي، بيروت: دار النهضة العربية. 
13- نبيل، عبد الهادي، عمر، نصر الله، سمير، اشقير، (2000)، بطء التعلم وصعوباته، عمان: دار وائل للنشر والتوزيع. ثانيًا: الدراسات السابقة:

1- الرصيص، ريم فهد،" فاعلية برنامج تعليمي بمساعدة الحاسوب في تعليم مهارة الجمع للتلاميذ ذوي التخلف العقلي البسيط" رسالة ماجستير، البحرين، كلية تربية، جامعة الخليج العربي، 2003 م. 2003 2- الشيباني، تامر بن محسن (2004) "تحديد الاحتياجات التدريبية لمعلمي صعوبات التعلم في تقنيات التعليم كما يراها أعضاء هيئة التدريس بقسمي وسائل وتكنولوجيا التعليم والتربية الحخاصة بجامعة الملك سعود ومشرفي ومعلمي صعوبات التعلم بوزارة التربية والتعليم"، رسالة ماجستير غير منشورة، الرياض، كلية التربية، جامعة الملك سعود. 3- العصيمي، عبد العزيز بن تُحَّه (2015)، "واقع استخدام التقنيات التعليمية الحديثة في غرفة المصادر والصعوبات التي يواجها معلمي ذوي صعوبات التعلم في منطقة القصيم"، رسالة ماجستير غير منشورة، كلية التربية، جامعة أم القرى. 4- عبد اللطيف، سليمان عبد العزيز (2010)، "برنامج مقترح لعلاج معوقات استخدام التقنيات التعليمية في برامج صعوبات التعلم في المرحلة الابتدائية"، رسالة ماجستير غير منشورة، الرياض، كلية التربية جامعة الملك سعود. 5- كريم، ليلى يوسف، (2009) " تشخيص القصور في بعض المهارات قبل الأكاديمية لأطفال الروضة "، إطروحة دكتوراه، تعز. ثالثًا: البجلات والدوريات:

1- قرشم، أحمد بن عفت، وحسين، هشام بن بركات(2010)، "برنامج مقترح لعلاج

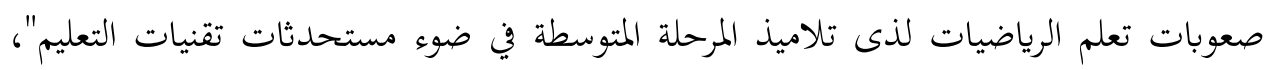
بحث منشور، الرياض، كلية التربية، مجلة جامعة الملك سعود، مجلد 24، 2012 م. 
2- كاشف، إيمان فؤاد،" فاعلية برنامج تدريبي لتنمية بعض المهارات المعرفية للتلاميذ ذوي

$$
\text { صعوبات التعلم"، المؤتمر الدولي لصعوبات التعلم، 19- } 19 \text { رابعًا: المراجع الأجنبية: } 22 \text { نوفمبر. }
$$

1- 21-Lewis \&Doorlag ,D.(1987).Teaching special students in the Mainstream. $2^{\text {nd }}$ ed., Columbus, Ohio: Charles E. Merrill.

2- Macarthur, C.(2001),Tehn010gy Applications for Students With Literacy Problems, Elementary School Journal.

$$
\text { خامسًا: المواقع الإلكترونية: }
$$

1. http://www.gulfkids.com/ar/indexphp?action=www.show_art\&artcat=1 $8 \& \mathrm{id}=793$

2. http://www.tgnyat.blogspot.com.12012\12 \blogpost_5054.hTml. 